\title{
High Cycle Fatigue Properties of a Minor Boron-Modified Ti-6Al-4V Alloy
}

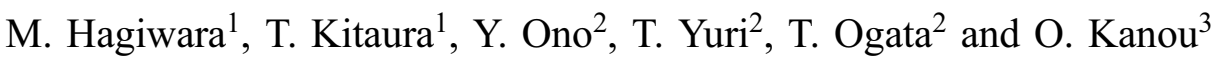 \\ ${ }^{1}$ Research Center for Advanced Eco-Fitting Technology, Kyushu Institute of Technology, Kitakyushu 808-0196, Japan \\ ${ }^{2}$ National Institute for Materials Science, Tsukuba 305-0047, Japan \\ ${ }^{3}$ Toho Titanium Co., Chigasaki 253-8510, Japan
}

Ti-6Al-4V alloys modified with minor amounts of boron (B) were prepared, and two types of microstructures, a full lamellar microstructure and an equiaxed microstructure, were generated through combinations of hot-deformation and heat treatments. The beneficial effect of adding a minor amount of B in refining microstructures was confirmed in as-cast ingots and a full lamellar microstructure. For example, a refined prior $\beta$ grain size of about $100 \mu \mathrm{m}$ in diameter was obtained for the 0.1 mass percent B-modified alloy with a full lamellar microstructure: accordingly, the size of each colony within the grains was reduced. Contrary to this, equiaxed microstructures with $\alpha$ grain sizes of about $8 \mu \mathrm{m}$ were obtained for both B-free and B-modified alloys. The room temperature high cycle fatigue (HCF) strength of the B-modified alloys increased compared to the B-free alloy for both microstructures. For example, HCF strength at $10^{7}$ cycles for the alloy with an equiaxed microstructure increased to $750 \mathrm{MPa}$ by the addition of $0.1 \% \mathrm{~B}$ from $650 \mathrm{MPa}$ for B-free alloy. The fatigue crack was found to originate neither from the TiB/matrix interface nor from the TiB itself but rather from the shear fractures across microstructural units such as colonies or spherical $\alpha$ phases. The reduced colony size and the retarding effect of TiB against the movement of the fatigue initiation area were thought to be responsible for the improved $\mathrm{HCF}$ properties of Ti-6Al-4V with lamellar and equiaxed microstructures, respectively.

[doi:10.2320/matertrans.M2012104]

(Received March 16, 2012; Accepted May 10, 2012; Published June 20, 2012)

Keywords: titanium-6aluminum-4vanadium alloy, boron, microstructure refinement, high cycle fatigue

\section{Introduction}

It has been demonstrated recently that the minor addition of boron (B) to titanium alloys produces a reduction in the as-cast grain size by roughly an order of magnitude compared to B-free alloys. As reported by Tamirisakandala et al., ${ }^{1)}$ the cast grain size of a $\mathrm{Ti}-6 \mathrm{Al}-4 \mathrm{~V}$ ingot reduces rapidly with increasing amounts of $\mathrm{B}$. At $\mathrm{B}$ concentrations above 0.1 mass percent $(\%)$, the grain size remains constant at around $100 \mu \mathrm{m}$. This grain refinement is attributed to the precipitation of $\mathrm{TiB}$ particles during the solidification process and their pinning effect against grain growth. ${ }^{1,2)}$ The reduced grain size is maintained after hot deformation processes and various heat treatments. Due to the grain refinement of the ingot, the extent of segregation is small, and the formation of a columnar microstructure is not so marked. This homogeneity of ingots can enable the elimination of ingot break down processes such as $\beta$ upset and $\beta$ working. Another beneficial effect of refined grain size is that it improves the tensile strength and ductility in the as-cast condition and significantly improves the hot workability. $^{3-5)}$ Thus, the addition of a minor amount of $\mathrm{B}$ contributes to titanium alloys in two respects: the reduction of manufacturing cost due to process simplification and the improvement of the material properties of manufactured products.

One concern of researchers regarding B-modified titanium alloys is the worry that the TiB formed in the alloy will cause early fatigue crack initiation, which would lead to the degradation of fatigue properties. However, the size of TiB has been reported to be very small (length: $\sim 2 \mu \mathrm{m}$, width: $<1 \mu \mathrm{m}),{ }^{6-8)}$ considerably smaller than a colony or the diameter of an equiaxed phase formed in the B-modified alloy. Therefore, it is expected that fatigue cracks would more likely arise from these larger microstructural units than from TiB.
Since the size of each colony in the full lamellar microstructure is, as will be shown in the text of this paper, smaller in the B-modified alloy than in the B-free alloy, it is further expected that the high-cycle fatigue (HCF) strength of the alloy with full lamellar microstructure will be increased by the minor addition of $\mathrm{B}$, because it has been convincingly shown that the sizes of colony and equiaxed $\alpha$ phase are the controlling factors in determining HCF strength in titanium alloys, and because the HCF strength increases as these sizes decrease. ${ }^{9-11)}$ In terms of the equiaxed-microstructure alloys, equiaxed microstructures with $\alpha$ grain sizes of about $5 \mu \mathrm{m}$ were obtained in the present study for both B-free and Bmodified alloys under the same deforming and heat treatment conditions. It was thus expected that B-free and B-modified alloys would show the same HCF strength. To confirm these three predictions first, that $\mathrm{TiB}$ is not the source of fatigue cracks, second, that the HCF strength of the B-modified alloy with full lamellar microstructure is higher than that of the Bfree counterpart and third, that the HCF strength of the Bmodified alloy with equiaxed microstructure is equal to that of the B-free counterpart, we conducted HCF tests on both Bfree and B-modified Ti-6Al-4V alloys. The Ti-6Al-4V alloy was chosen for the present study because it is the most widely used titanium alloy in various industrial applications due to a combination of attractive mechanical properties.

\section{Experimental}

B-free and 0.1 mass $\%$ B-containing cylindrical ingots about $70 \mathrm{~mm}$ in diameter and about $60 \mathrm{~mm}$ long were prepared via the levitation melting method at the National Institute for Materials Science, Tsukuba, Japan. The alloy ingots were hot-forged to rectangular billets with dimensions of $38 \times 38 \times \sim 150 \mathrm{~mm}^{3}$ at $930^{\circ} \mathrm{C}$ to break the columnar microstructure. These hot-forged billets were then hot barrolled at $930^{\circ} \mathrm{C}$ into $12-\mathrm{mm}$ square bars, which were used 
after appropriate heat treatments for tensile and HCF tests. In addition, B-free, 0.05 mass $\%$ B- and 0.1 mass $\%$ B-modified cylindrical $\mathrm{Ti}-6 \mathrm{Al}-4 \mathrm{~V}$ ingots of about $40 \mathrm{~mm}$ in diameter were prepared using a W-electrode arc-melting furnace for the experiments designed to confirm the beneficial effect of $B$ on the refinement of ingot microstructures and the suppression of prior $\beta$ grain growth.

To generate a full lamellar microstructure, the levitationmelted, hot-forged and hot-rolled bars were annealed at $1050^{\circ} \mathrm{C}$ in the single bcc $(\beta)$ phase region for $1 \mathrm{~h}$ followed by slow cooling at the controlled cooling rate of $0.03 \mathrm{~K} \mathrm{~s}^{-1}$. To produce an equiaxed microstructure, these hot-rolled bars were annealed at $930^{\circ} \mathrm{C}$ in the $(\alpha+\beta)$ two-phase region followed by slow cooling at the controlled cooling rate of $0.03 \mathrm{~K} \mathrm{~s}^{-1}$. Finally all bars were held at $700^{\circ} \mathrm{C}$ for $1 \mathrm{~h}$ to stabilize the microstructure.

Tensile tests at room temperature were performed in air with specimens $3.5 \mathrm{~mm}$ in diameter and $16 \mathrm{~mm}$ in length. The $\mathrm{HCF}$ tests were done with specimens $3.0 \mathrm{~mm}$ in diameter and $13 \mathrm{~mm}$ in length in pull-pull mode at an $R$ (ratio of minimum stress to maximum stress) of 0.1 in the load-control mode, and a frequency of $10 \mathrm{~Hz}$. Microstructural and fractographic observations were made on an optical microscope (OM), a scanning electron microscope (SEM) and a backscattered electron microscope (BSE), which revealed the morphology and finer structural details of the micro-constituents more distinctively than SEM.

\section{Results and Discussion}

\subsection{Microstructures}

\subsubsection{As-cast microstructures}

OM micrographs taken from the arc-melted and cast B-free and B-modified alloy ingots are shown in Fig. 1, which clearly illustrate the grain refinement effect caused by B addition. With the addition of 0.05 mass $\% \mathrm{~B}$, the grain size and columnar microstructure were drastically reduced (Fig. 1(b)) compared to that of the B-free alloy (Fig. 1(a)). However, the central area of the ingot still exhibited a coarse columnar structure. With the addition of 0.1 mass $\% \mathrm{~B}$, the coarse columnar structure disappeared and thereby the refined microstructure was obtained in the whole area of the ingot (Fig. 1(c)). The prior $\beta$ grain size measurement revealed, as shown in Fig. 2, that the addition of 0.1 mass\% $\mathrm{B}$ effectively refined the average prior $\beta$ grain size from $\sim 1000$ (Fig. 2(a)) to $100 \sim 300 \mu \mathrm{m}$ (Fig. 2(b)). The refined prior $\beta$ grains were decorated with whisker-like TiB, produced in situ by the addition of B.

To further confirm the beneficial effect of $B$ on the suppression of the grain growth of $\mathrm{Ti}-6 \mathrm{Al}-4 \mathrm{~V}$, the hot barrolled samples were held at $1100^{\circ} \mathrm{C}$ in the single $\beta$-phase region, and the size of prior $\beta$ grains was measured as a function of holding time, as shown in Fig. 3, where, although the grain size of the B-free alloy increased rapidly with increases in holding time, the grain stabilization caused by the addition of a small amount of B was clearly evident. It has been reported that $\mathrm{B}$ is completely soluble in liquid phase titanium but the solubility in $\beta$ or $\alpha$ phases is almost negligible, ${ }^{12}$ which makes TiB a very effective inoculant in restricting the $\beta$ grain boundary mobility by pinning. ${ }^{2)}$
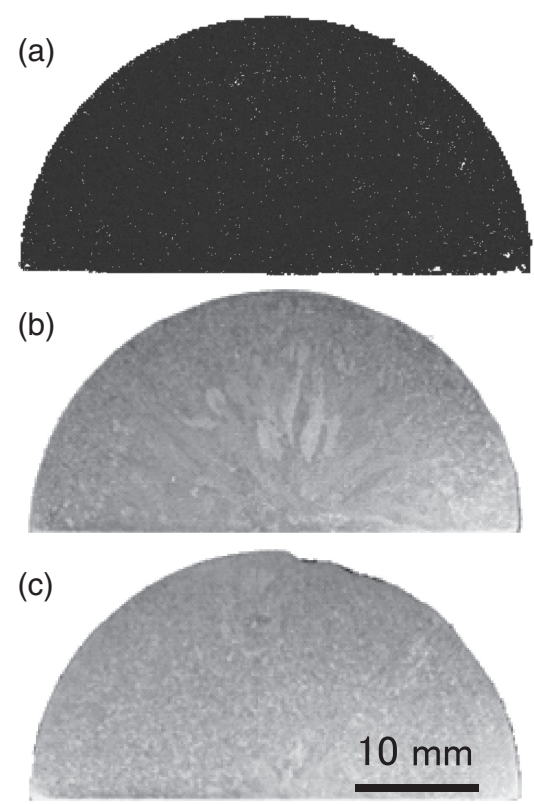

Fig. 1 OM micrographs of (a) B-free, (b) 0.05 mass $\%$ B-modified and (c) 0.1 mass $\%$ B-modified Ti-6 Al-4V ingots.
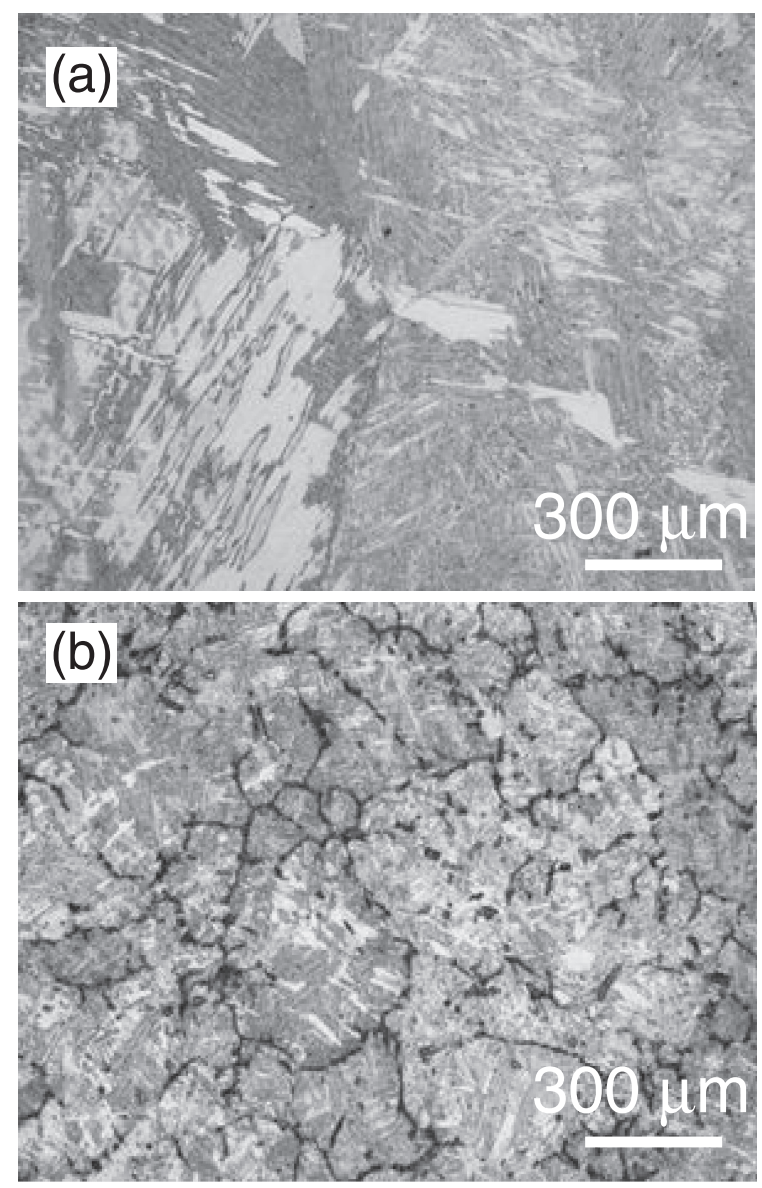

Fig. 2 Higher-magnification OM micrographs of (a) B-free and (b) 0.1 mass \% B-modified Ti-6Al-4V ingots.

Tamirisakandala et al. previously discussed the mechanism of grain refinement of Ti alloys such as Ti-6Al-4V and Ti-6Al-2Sn-4Zr-2Mo-0.1Si via B addition. ${ }^{1)}$ They hypothesized the mechanism as an effect of constitutional super- 


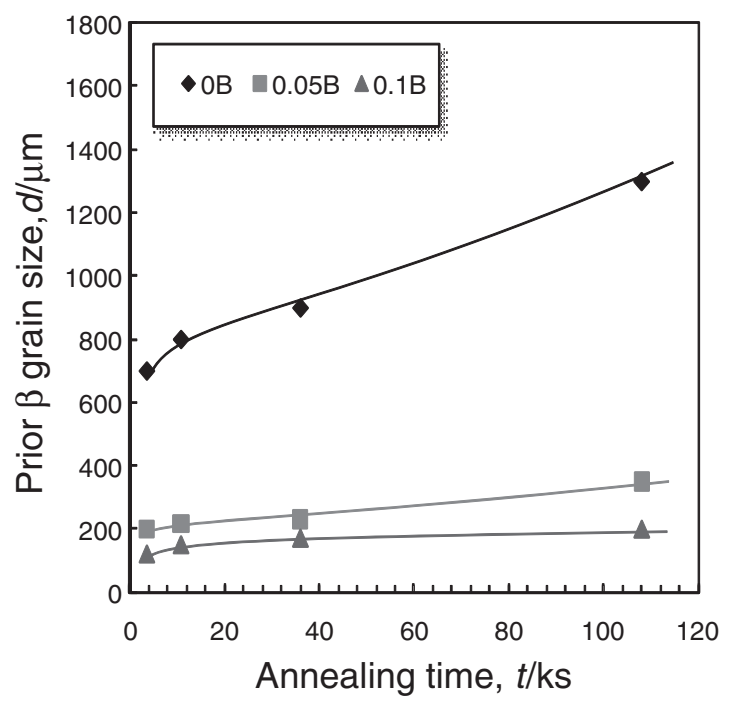

Fig. 3 Variation of prior $\beta$ grain size as a function of annealing time at $1100^{\circ} \mathrm{C}$ for B-free, 0.05 mass $\%$ B-modified and 0.1 mass $\%$ B-modified Ti-6Al-4V alloys.

cooling caused by the $\mathrm{B}$ rejected from the primary $\beta$-Ti grains into the liquid ahead of the solidification front and its influence on the nucleation and growth rate, and not because TiB acts as a nucleating agent.

\subsubsection{Lamellar microstructures}

Figure 4 shows SEM micrographs taken on planes parallel to the rolling direction. The B-free alloy shows a typical lamellar microstructure with packets or colonies of similarly aligned $\alpha$ phase laths (hcp structure, dark gray phase) and $\beta$ phases (bcc structure, white phase) between laths, and a massive $\alpha$ phase at the grain boundaries (Fig. 4(a)). There are white-colored long and narrow bands or streaks aligning along the rolling direction in the B-modified alloy. The spacing between two adjacent streaks is irregular, i.e., ranging from about 30 to about $70 \mu \mathrm{m}$ (Fig. 4(b)). It seems that the aggregate of $\mathrm{TiB}$ originally located at the grain boundaries in a cast ingot (see Fig. 2(b)) was untangled and dispersed in one direction during the hot bar-rolling process. Due to the presence of these streaks of TiB, it seemed that the growth of $\beta$ grains was blocked when the hot bar-rolled Bmodified alloy was held in the single $\beta$-phase region and accordingly, a reduced grain size of the order of $100 \mu \mathrm{m}$ and refined colonies with diameters of about $50 \mu \mathrm{m}$ within the grains were obtained. The size of each $\mathrm{TiB}$ seems to be $1 \sim 2 \mu \mathrm{m}$ with an aspect ratio of $\sim 10$.

\subsubsection{Equiaxed microstructures}

Figure 5 shows equiaxed microstructures of the B-free and 0.1 mass \% B-modified alloys. Contrary to the modification to full-lamellar microstructures, quite the same equiaxed microstructures with the $\alpha$ grain size of about $8 \mu \mathrm{m}$ were obtained for both alloys. In the area between $\alpha$ phases, there are very refined lamellar microstructures composed of elongated $\alpha$ phases and $\beta$ phases. As shown in Fig. 5(b), the spacing of adjacent streaks of TiB was far wider, i.e., $\sim 30$ to $\sim 70 \mu \mathrm{m}$, than the size of the equiaxed $\alpha$ phases: thus, the growing front of most $\alpha$ phases in the B-modified alloy seemed not to have reached the streaks, which would have resulted in the same size of equiaxed $\alpha$ phases as that of the B-free alloy.
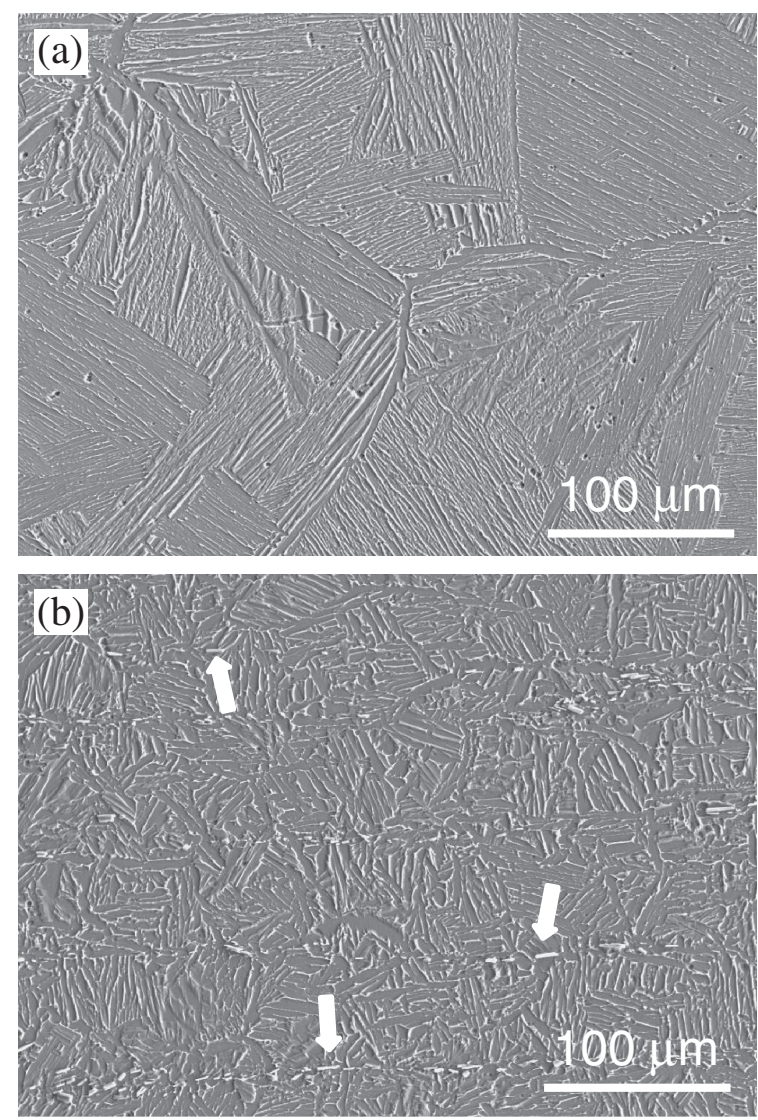

Fig. 4 BSE micrographs of (a) B-free and (b) 0.1 mass $\%$ B-modified Ti$6 \mathrm{Al}-4 \mathrm{~V}$ alloys with lamellar microstructure. The arrows indicate TiB.
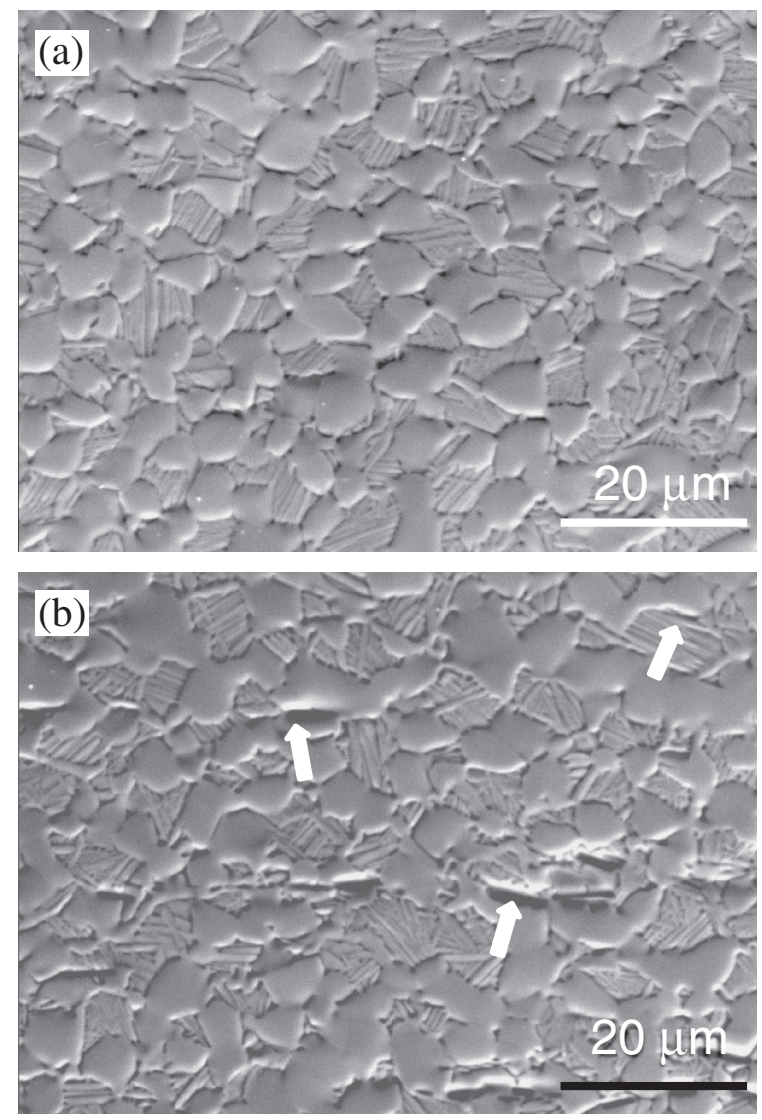

Fig. 5 SEM micrographs of (a) B-free and (b) 0.1 mass\% B-modified Ti$6 \mathrm{Al}-4 \mathrm{~V}$ alloys with equiaxed microstructure. The arrows indicate TiB. 


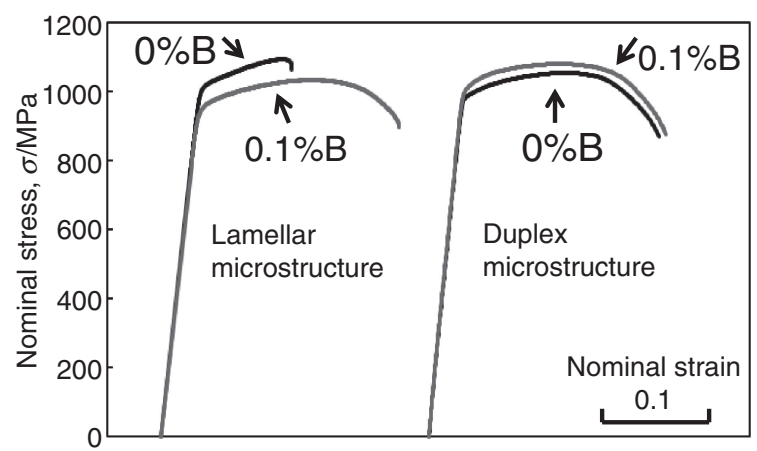

Fig. 6 Tensile curves of B-free and 0.1 mass $\%$ B-modified Ti-6Al-4V alloys with lamellar and duplex microstructures at room temperature.

Table 1 A summary of tensile properties of B-free and B-modified Ti-6Al$4 \mathrm{~V}$ alloys at room temperature.

a: hot bar-rolled

\begin{tabular}{cccccc}
\hline \multirow{2}{*}{ Alloy } & $\begin{array}{c}\text { Micro- } \\
\text { structure }\end{array}$ & $\begin{array}{c}0.2 \% \text { YS } \\
\text { MPa }\end{array}$ & $\begin{array}{c}\text { TS } \\
\text { MPa }\end{array}$ & $\begin{array}{c}\text { U.EL } \\
\%\end{array}$ & $\begin{array}{c}\text { T.EL } \\
\%\end{array}$ \\
\cline { 1 - 4 } Ti-6Al-4V & \multirow{2}{*}{ Lamellar } & 1007 & 1098 & 7.2 & 7.8 \\
\cline { 4 - 6 } Ti-6Al-4V-0.1B & & 939 & 1034 & 10.2 & 19.3 \\
\hline \multirow{2}{*}{ Ti-6Al-4V } & \multirow{2}{*}{ Duplex } & 979 & 1053 & 8.5 & 18.8 \\
\cline { 1 - 1 } Ti-6Al-4V-0.1B & & 998 & 1080 & 8.8 & 19.4 \\
\hline
\end{tabular}

b: hot sheet-rolled

\begin{tabular}{ccccccc}
\hline \multirow{2}{*}{ Alloy } & $\begin{array}{c}\text { Micro- } \\
\text { structure }\end{array}$ & Direction & $\begin{array}{c}0.2 \% Y S \\
\mathrm{MPa}\end{array}$ & $\begin{array}{c}\text { TS } \\
\mathrm{MPa}\end{array}$ & $\begin{array}{c}\text { U.EL } \\
\%\end{array}$ & $\begin{array}{c}\text { T.EL } \\
\%\end{array}$ \\
\hline \multirow{2}{*}{ Ti-6Al-4V } & \multirow{2}{*}{ Duplex } & $\mathrm{L}$ & 868 & 917 & 7 & 15 \\
\cline { 3 - 7 } & & $\mathrm{T}$ & 847 & 888 & 6 & 14 \\
\cline { 3 - 6 } Ti-6Al-4V-0.1B & $\mathrm{L}$ & 866 & 908 & 7 & 16 \\
\cline { 3 - 6 } & & $\mathrm{T}$ & 891 & 919 & 7 & 14 \\
\hline
\end{tabular}

Y.S: Yield Stress, TS: Tensile Strength, U.EL: Uniform Elongation, T.EL: Total Elongation

\subsection{Tensile behaviors}

Figure 6 shows the tensile curves of levitation-melted and hot bar-rolled B-free and B-modified alloys with lamellar and equiaxed microstructures tested at room temperature. The actual tensile data are shown in Table 1, which indicate that, for alloys with lamellar microstructures, the addition of a 0.1 mass $\%$ B greatly increased the tensile elongation and slightly reduced the ultimate tensile strength. The total tensile elongation was increased from 7 to $19 \%$, indicating the beneficial effect of $\mathrm{B}$ in improving tensile elongation due to microstructural refinement. Contrary to this, both B-free and B-modified alloys with equiaxed microstructures exhibited almost the same $0.2 \%$ proof stress, tensile strength and elongation, which would be the reflection of the same equiaxed microstructures being exhibited by both alloys.

\subsection{High-cycle fatigue properties}

\subsubsection{Lamellar microstructure}

The HCF test results on B-free and B-modified alloys with lamellar microstructures are shown in Fig. 7. This figure (Fig. 7(a)) clearly reveals that the B-modified alloy exhibits
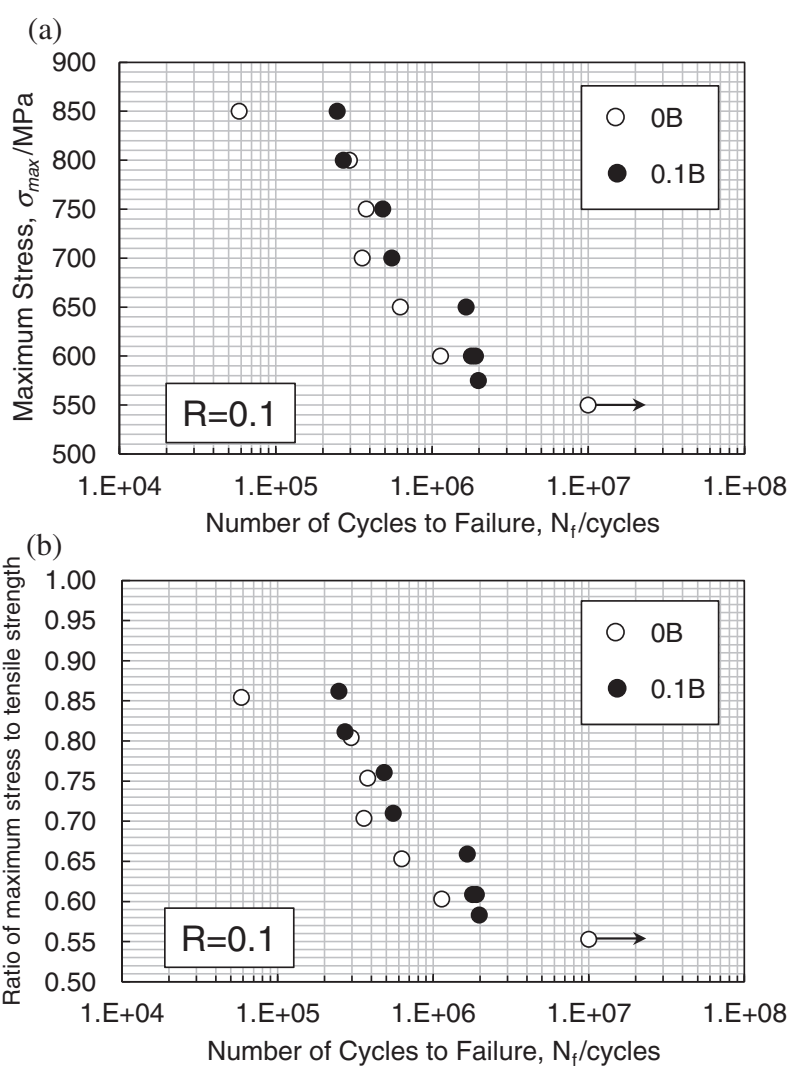

Fig. 7 High cycle fatigue of B-free and 0.1 mass $\%$ B-modified Ti-6Al-4V alloys with lamellar microstructure. (a) Plots of maximum stress, $\sigma_{\max }$ vs. number of cycles to failure, $N_{\mathrm{f}}$. (b) Plots of fatigue ratio (maximum stress/ tensile strength) vs. number of cycles to failure.

higher HCF strength in the cycle range up to $10^{6}$ cycles. For example, an increase in $\mathrm{HCF}$ strength of about $50 \mathrm{MPa}$ was obtained at $10^{6}$ cycles. Thus, it was confirmed that the minor addition of $\mathrm{B}$ had no detrimental effect but rather a beneficial effect on the HCF behavior of the Ti-6Al-4V alloy.

SEM micrographs of the fatigue fracture surface taken from the B-free alloy specimen with lamellar microstructure are shown in Fig. 8. The fatigue specimen failed due to a subsurface initiation, as indicated by the circle in Fig. 8(a). Sub-surface fatigue initiation has commonly been reported in conventional titanium alloys regardless of their microstructures when the HCF test is conducted in a pull-pull mode, namely when conducted at an $R$ ratio (= minimum stress/ maximum stress) greater than zero. ${ }^{9-14)}$ The higher-magnification SEM micrograph showed rough fracture morphology with several coarse facets evident at the fatigue crack initiation site (Fig. 8(b)). The size of each facet seems to correspond to that of one colony of similarly aligned laths in the lamellar microstructure. This rough multi-facet initiation morphology has generally been observed at the fatigue crack initiation site when titanium alloys with lamellar microstructures are fatigue-tested..$^{9-11)}$ SEM micrographs of the fatigue fracture surface taken from the B-modified alloy specimen with refined lamellar microstructure are shown in Fig. 9. A few flat facets each $\sim 80 \mu \mathrm{m}$ in diameter were present at the fatigue initiation site (Fig. 9(a)). The size of these facets corresponded to that of the colonies (Fig. 4(b)). Careful examination of the fatigue crack initiation site 

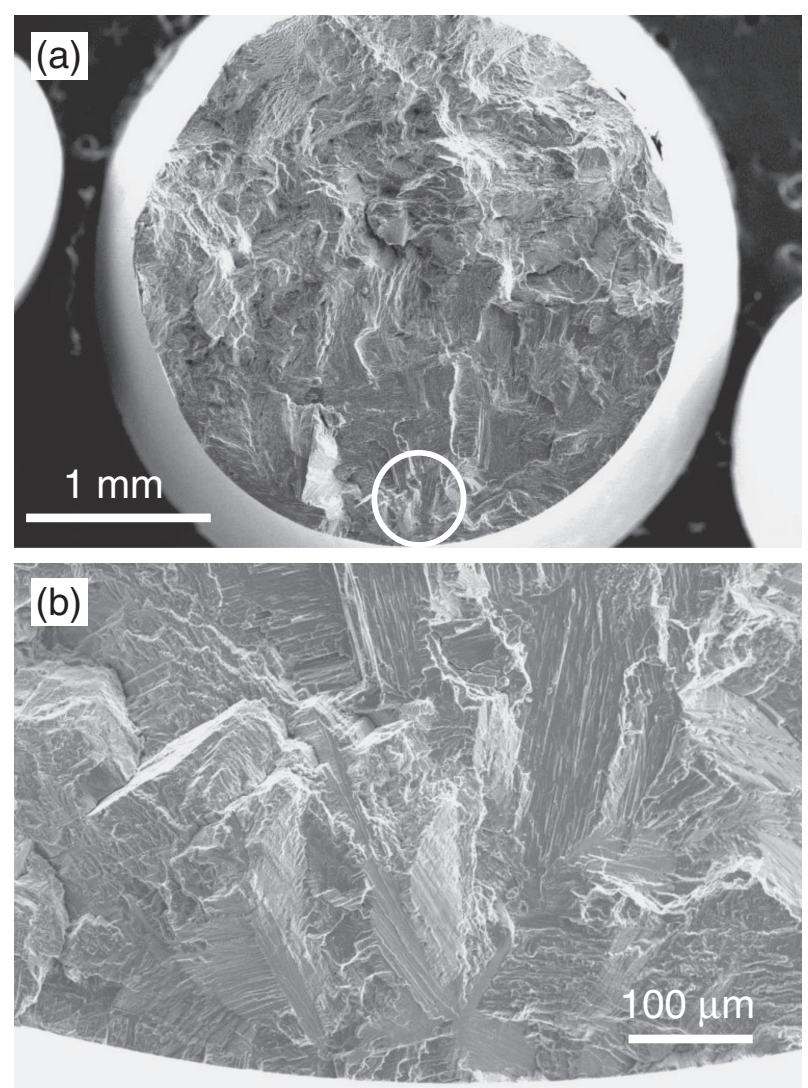

Fig. 8 A typical fatigue fracture surface taken from the B-free Ti-6Al-4V alloy specimen with lamellar microstructure (maximum stress, $\sigma_{\max }=$ $650 \mathrm{MPa}$, number of cycles to failure, $N_{\mathrm{f}}=6.3 \times 10^{5}$ cycles). (a) Whole view. The circle indicates the fatigue initiation site. (b) Higher magnification SEM micrograph of the fatigue initiation site.

by BSE showed no presence of $\mathrm{TiB}$ on the flat facet (Fig. 9(b)).

Based on the morphological observations described above, it is therefore reasonable to consider that the fatigue initiated neither from $\mathrm{TiB}$ itself nor from the $\mathrm{TiB} /$ matrix interface but rather from a microstructural unit of the matrix alloy, i.e., from a colony.

\subsubsection{Duplex microstructure}

Figure 10 shows the fatigue curves of Ti-6Al-4V with equiaxed microstructures. By comparing this figure with Fig. 7, it is evident that the HCF strength of a B-free alloy with equiaxed microstructure was considerably higher than that of B-free alloy with lamellar microstructure in the whole cycle range examined, which would be the natural manifestation of the fact that a microstructural unit of spherical $\alpha$ phase in the equiaxed microstructure is much finer than the colony in the lamellar microstructure.

The B-modified alloy showed a considerably higher $\mathrm{HCF}$ strength compared to those of the B-free alloy. For example, the HCF strength at $10^{7}$ cycles increased from $\sim 700$ to $\sim 800 \mathrm{MPa}$ by the addition of 0.1 mass $\% \mathrm{~B}$.

SEM micrographs of fatigue fracture surfaces taken from the B-free alloy specimens with equiaxed microstructure are shown in Fig. 11. The sub-surface fatigue crack initiation site in Fig. 11(a) is indicated by a circle. The higher-magnification SEM micrograph of initiation site reveals the presence of multiple clusters or an agglomerated cluster of flat facets at
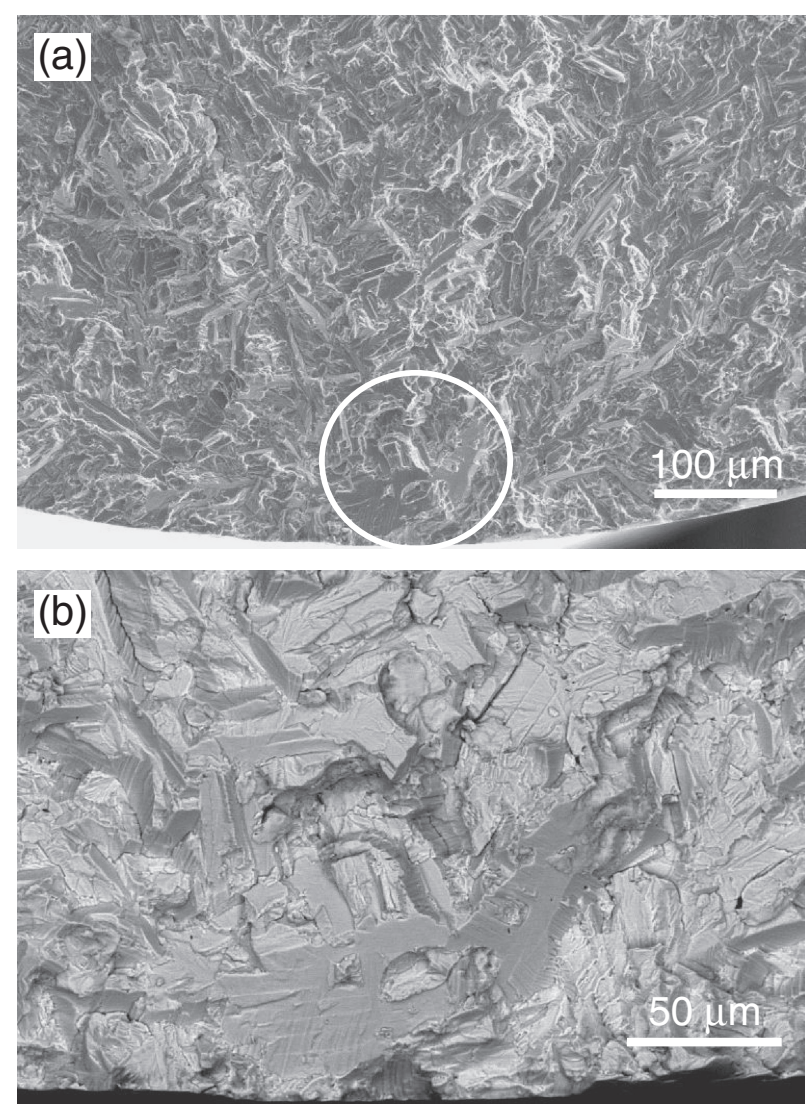

Fig. 9 A typical fatigue fracture surface taken from the $0.1 \mathrm{mass} \%$ B-modified Ti-6Al-4V alloy specimen with lamellar microstructure (maximum stress, $\sigma_{\max }=650 \mathrm{MPa}$, number of cycles to failure, $N_{\mathrm{f}}=$ $1.66 \times 10^{6}$ cycles). (a) Whole view. The circle indicates the fatigue initiation site. (b) Higher magnification BSE micrograph of the fatigue initiation site.

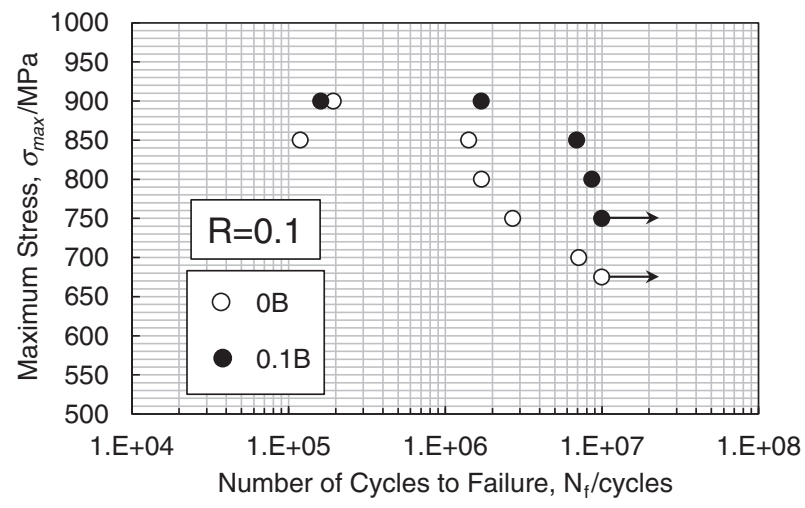

Fig. 10 High cycle fatigue of B-free and 0.1 mass $\%$ B-modified Ti-6Al$4 \mathrm{~V}$ alloys with equiaxed microstructure.

the initiation site, as indicated by circles in Fig. 11(b). This type of multiple-facet initiation was observed for all fatigue specimens used in the whole maximum stress $\left(\sigma_{\max }\right)$ range from 750 to $900 \mathrm{MPa}$. The size of each flat facet was about $8 \mu \mathrm{m}$ in diameter. This size seems to correspond closely to that of a spherical $\alpha$-phase in the microstructure. Figure 12 shows SEM micrographs of fatigue fracture surfaces taken from the B-modified alloy specimens with equiaxed microstructure. The overall morphology of the fatigue fracture 

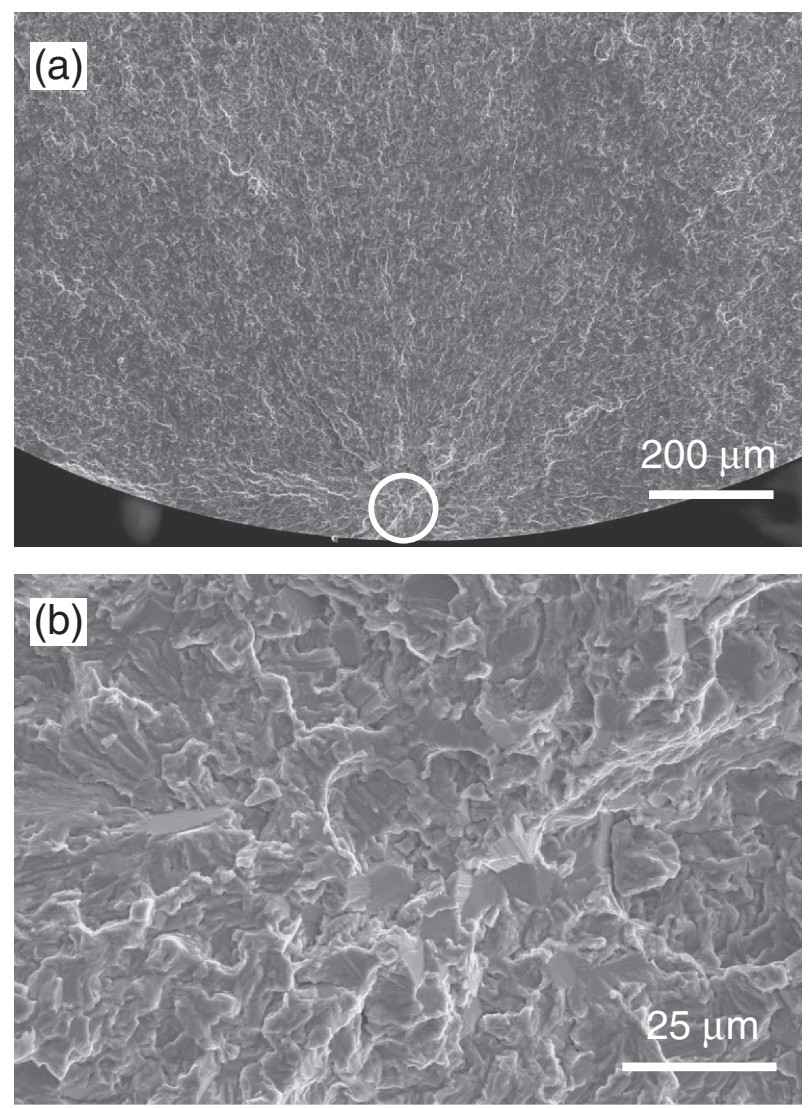

Fig. 11 A typical fatigue fracture surface taken from the B-free Ti-6Al-4V alloy specimen with equiaxed microstructure (maximum stress, $\sigma_{\max }=$ $800 \mathrm{MPa}$, number of cycles to failure, $N_{\mathrm{f}}=1.7 \times 10^{6}$ cycles). (a) Whole view. The circle indicates the fatigue initiation site. (b) Higher magnification SEM micrograph of the fatigue initiation site.

surface is quite similar to that of B-free alloy (Fig. 12(a)). The three stages of fatigue fracture, namely, fatigue crack initiation, fatigue propagation and fast fracture can be clearly seen on the fracture surface. The diameters of the initiation stage and propagation region seem to be $100-200$ and $800 \mu \mathrm{m}$, respectively. The higher-magnification SEM micrograph (Fig. 12(b)) and BSE image (Fig. 12(c)) of the fatigue initiation reveal that the trace of fatigue fracture of each facet in the B-modified alloy is not so clearly reflective of corresponding equiaxed microstructure compared to that in the B-free alloy (Fig. 12(a)). These micrographs also show no presence of $\mathrm{TiB}$ on the fracture surface; thus, it seems reasonable to consider that the fatigue crack was not initiated at TiB but rather from the shear fractures across the spherical $\alpha$-phases.

\subsubsection{Mechanism of HCF improvement}

Improved tensile strength and microstructural refinement are known to be the two main factors contributing to the increase in HCF strength of Ti alloys. ${ }^{9-11)}$ For the case of Ti-6Al-4V alloys with lamellar microstructures, the tensile strength of the B-modified alloy was a little bit lower than that of B-free alloy, as shown in Fig. 6 and Table 1. So the observed HCF improvement can be attributed to microstructural refinement. To describe the contribution from the microstructural refinement more explicitly, it is demonstrative to calculate the fatigue ratio of HCF strength to tensile strength $\left(\sigma_{\max } / \mathrm{TS}\right)$. As shown in Fig. 7(b), the
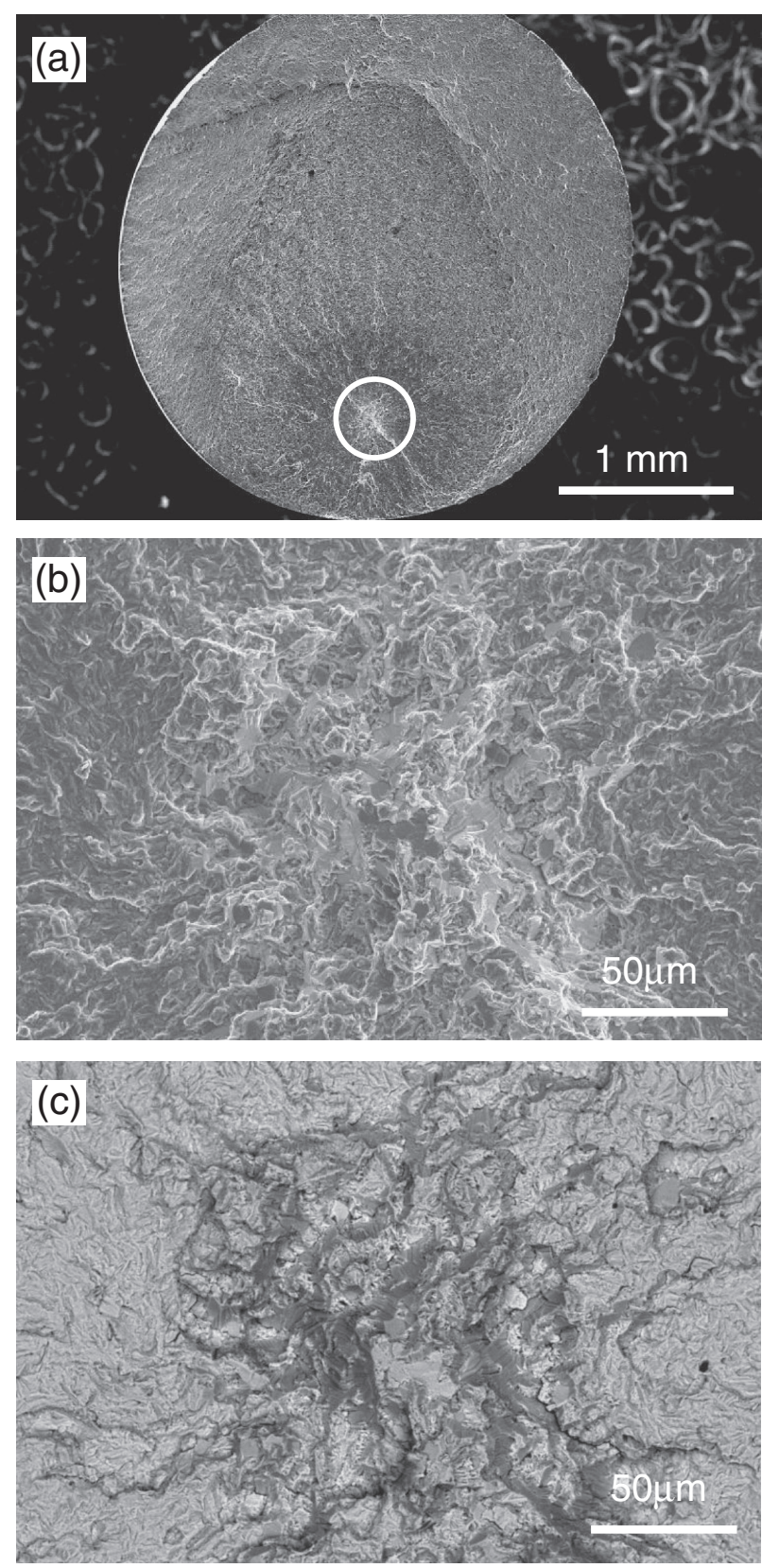

Fig. 12 A typical fatigue fracture surface taken from the 0.1 mass $\%$ Bmodified Ti-6Al-4V alloy specimen with equiaxed microstructure (maximum stress, $\sigma_{\max }=800 \mathrm{MPa}$, number of cycles to failure, $N_{\mathrm{f}}=8.7 \times 10^{6}$ cycles). (a) Whole view. The circle indicates the fatigue initiation site. (b) Higher magnification SEM micrograph of the fatigue initiation site. (c) Higher magnification BSE micrograph of Fig. 12(b).

overall trend of the fatigue ratio curve, i.e., $\sigma_{\max } / \mathrm{TS}$ vs. cycles curve, is quite similar to that of the B-free alloy. These two figures clearly indicate that the improvement of fatigue strength is mainly the result of refinement of the lamellar microstructure.

Based on the concurrent observation of initiation facets and underlying microstructures for $(\alpha+\beta)$-type Ti-6Al-4V and $(\mathrm{O}+\mathrm{B} 2)$-type orthorhombic Ti-22Al-27Al alloys with lamellar microstructures, Hagiwara previously proposed that fatigue cracks were initiated by shear fractures across a colony. $\left.{ }^{9}, 10\right)$ It seems reasonable that the fatigue crack in the present B-free and B-modified alloys with lamellar micro- 
structures would be initiated by the same mechanism as reported by Hagiwara. Namely, the fatigue crack was initiated from the shear fracture across a colony. It is well known that the size of the colony or spherical equiaxed $\alpha$ grains is the controlling factor in determining HCF strength in titanium alloys, and the HCF strength decreases as the size increases. The lower HCF strength of titanium alloys with large colony microstructures can be explained on the basis of the long slip path of this microstructure, since a large colony can be considered to be a large single crystal, and thus the long slip path across the colony can easily cause the slippingoff of the intense slip bands and a large stress concentration at the colony or grain boundaries. ${ }^{9-11)}$ As has been shown in the present paper, the B-modified alloy with lamellar microstructure exhibited reduced colony sizes. Therefore, the reduced colony size, which corresponds to the shorter slip length, can be regarded as responsible for the higher HCF strength exhibited by the B-modified Ti-6Al-4V alloy with lamellar microstructure.

For the case of the B-free and B-modified alloys with equiaxed microstructures, both alloys showed almost the same $0.2 \%$ proof stress and tensile strength (Table 1) and microstructures (Fig. 5) under the same hot-deforming and heat-treatment conditions. Therefore, we predicted, as described previously, that the HCF strength of B-modified alloy would coincide with that of the B-free alloy. However, contrary to this prior prediction, the B-modified alloy showed a considerably higher HCF strength in the whole cycle range examined (Fig. 10).

It is shown that the HCF process can be divided into three stages: the fatigue crack initiation (Stage I), fatigue crack propagation (Stage II) and fast fracture (Stage III). It is also well documented that the majority of the fatigue life (more than $90 \%$ ) is spent in Stage I. ${ }^{11)}$ So the present discussion on the mechanism of fatigue improvement for the B-modified alloy places emphasis on the Stage I, and fatigue improvement during Stage II and Stage III is excluded from the discussion.

Umezawa and Nagai ${ }^{15)}$ have previously observed multiple clusters or an agglomerated cluster of flat facets, as was observed in the present study, at the fatigue crack initiation site in Ti-6Al-4V alloys when fatigue-tested at cryogenic temperatures. In discussing the mechanism of fatigue crack initiation, they showed that the critical size of the Stage I necessary to transfer to the Stage II was highly dependent on the maximum stress $\left(\sigma_{\max }\right)$, and that this size increased as the $\sigma_{\max }$ decreased. For example, the critical sizes were shown to be $>40 \mu \mathrm{m}$ and around $5 \mu \mathrm{m}$ when fatigue-tested at $4 \mathrm{~K}$ under the condition of $\sigma_{\max }=800 \mathrm{MPa}$ and $1000 \sim 1400 \mathrm{MPa}$, respectively. They also showed that as the $\sigma_{\max }$ is decreased, the morphology of the subsurface crack initiation sites was changed from single-faceted to multi-faceted. These facets were found to be the traces of the slipping-off of $\alpha$ phases. The diameter of each $\alpha$ phase in the conventional Ti-6Al-4V alloy is usually on the order of $\sim 10 \mu \mathrm{m}$; thus, when fatiguetested under the lower $\sigma_{\max }$ condition, both the slipping-off of multiple $\alpha$ phases and the connection of these $\alpha$ phases crossing the $\beta$ phase plates between them are needed to reached the critical size which is supposed to be larger at room temperature than $(>40 \mu \mathrm{m})$ at $4 \mathrm{~K} .^{15)}$
As shown in Fig. 7(a) and Fig. 9(a), the diameter of the fatigue crack initiation area and the spacing of TiB bands or streaks in the hot bar-rolled specimens are 100 and $30 \sim 70 \mu \mathrm{m}$, respectively. Therefore, for the fatigue initiation front to reach the critical size of $100 \mu \mathrm{m}$, the moving front of fatigue initiation area must interact these $\mathrm{TiB}$ bands plural times. During this moving process, TiB has the strong potential to block the movement of the fatigue initiation area, which would have the effect of slowing the process of the fatigue initiation area reaching the critical size and thus lead to prolonged fatigue life compared to that of the B-free specimen.

Since whisker-like TiB compounds align parallel to the hot-rolling direction, if the fatigue crack proceeds parallel to $\mathrm{TiB}$ orientation, the fatigue initiation front is unlikely to encounter $\mathrm{TiB}$ frequently, which will result in the minor fatigue improvement. On the contrary, if the fatigue crack proceeds perpendicularly to the TiB orientation, there is a good possibility of the fatigue initiation front encountering $\mathrm{TiB}$, which will lead to much greater fatigue improvement. To confirm our hypothesis about the retarding effect of TiB against fatigue crack progression and its orientation dependence of TiB in a uni-axially hot sheet-rolled Ti-6Al-4V with equiaxed microstructures, we performed the following fatigue test.

The levitation-melted B-free and 0.1 mass $\%$ B-containing cylindrical ingots about $70 \mathrm{~mm}$ in diameter and about $60 \mathrm{~mm}$ long were hot sheet-rolled at $930^{\circ} \mathrm{C}$ into $\sim 70$-mm-wide and 12-mm-thick rectangular-shaped plates, which subsequently received the same heat treatment as the hot bar-rolled materials to produce equiaxed microstructures. Fatigue specimens with longitudinal directions parallel (denoted by L-specimen) and perpendicular (denoted by T-specimen) to the rolling direction were cut from these plates. The schematic configuration of test specimens and their relationship between fatigue crack direction and TiB orientation are shown in Fig. 13.

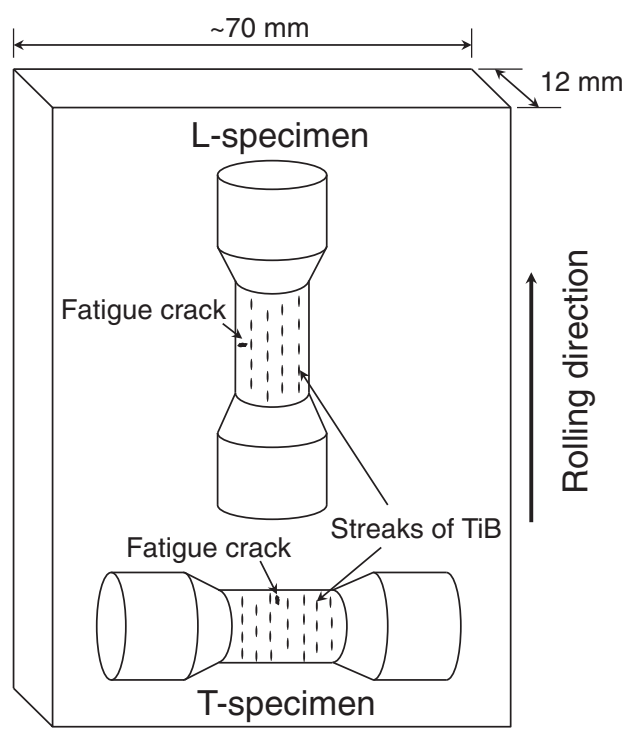

Fig. 13 Schematic configuration of fatigue specimens and the orientation relationship between fatigue crack direction and $\mathrm{TiB}$ in the hot sheetrolled $\mathrm{Ti}-6 \mathrm{Al}-4 \mathrm{~V}$. 


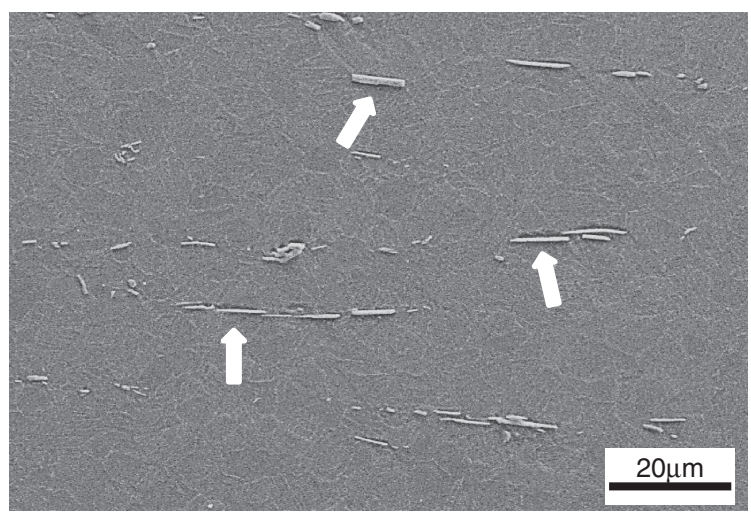

\section{Rolling direction}

Fig. 14 SEM micrograph of hot sheet-rolled 0.1 mass\% B-modified Ti$6 \mathrm{Al}-4 \mathrm{~V}$ alloy with equiaxed microstructure. The arrows indicate TiB.

Figure 14 shows equiaxed microstructures of the B-free and 0.1 mass $\%$ B-modified alloys subjected to the hot platerolling and heat treatments. Similar to the case of hot barrolling, $\alpha$ grain sizes of about $8 \mu \mathrm{m}$ were obtained for both alloys. The spacing of adjacent streaks of TiB was quite similar to that of the hot bar-rolled material. As shown in Table 1, in each of the B-free and B-modified alloys, Lspecimens and T-specimens showed the same $0.2 \%$ proof stress, tensile strength and tensile elongation, which indicates that the texture formation during hot plate-rolling had almost no effect on the tensile and fatigue properties.

As can be seen from Fig. 15, there was no difference in the HCF strength (Fig. 15(a)) and even in the HCF strength/ tensile strength (Fig. 15(b)) between L-specimens and Tspecimens taken from the B-free alloy. The HCF strength of L-specimens and T-specimens was increased by the addition of 0.1 mass \% B. Importantly, however, the degree of fatigue improvement in the L-specimens was clearly higher than that in T-specimens, evidence that the interaction between the fatigue initiation area and $\mathrm{TiB}$ was much stronger in the Lspecimens. These results support our speculation that TiB has the effect of retarding the expansion of the fatigue initiation area and that the interaction between the fatigue initiation area and $\mathrm{TiB}$ is much stronger when $\mathrm{TiB}$ is aligned parallel to the longitudinal axis of fatigue specimen due to the increased likelihood of $\mathrm{TiB}$ intersecting with the moving front of the fatigue initiation area. The fact that the initiation site of the Bmodified alloy did not have such clear-cut features compared to the B-free alloy might be a result of this interaction between TiB and the moving front.

As shown in Fig. 4(b), most of refined colonies with the size of about $50 \mu \mathrm{m}$ in the B-modified alloy with lamellar microstructure lie between two adjacent TiB bands or streaks. This size seems to be comparable to that of the critical size of the fatigue initiation area for entering Stage II of fatigue, i.e., more than $40 \mu \mathrm{m}$, and thereby fatigue cracking of one colony might be enough for Stage I of the fatigue process. For this reason, the interaction of TiB with the moving front of fatigue crack initiation might not be caused during Stage I and thus, contrary to the case of equiaxed microstructure, the existence
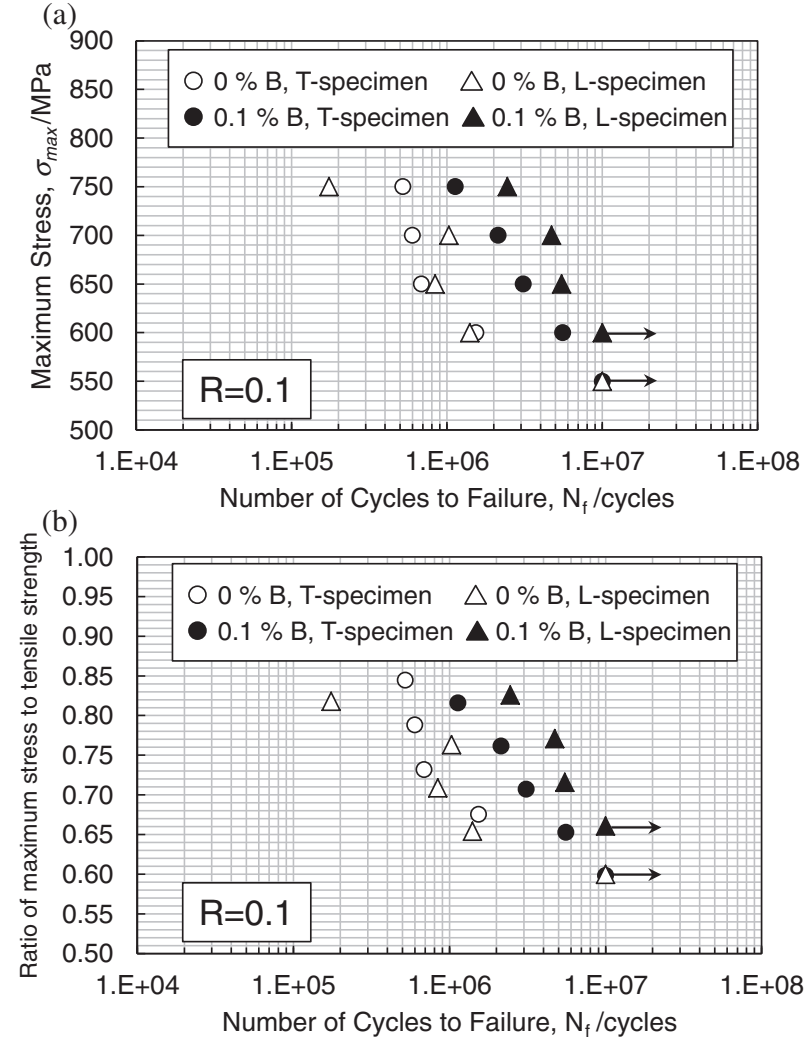

Fig. 15 High cycle fatigue of hot sheet-rolled B-free and 0.1 mass $\%$ Bmodified Ti-6Al-4V alloys with equiaxed microstructures. (a) Plots of maximum stress, $\sigma_{\max }$ vs. number of cycles to failure, $N_{\mathrm{f}}$. (b) Plots of fatigue ratio (maximum stress/tensile strength) vs. number of cycles to failure, $N_{\mathrm{f}}$.

of $\mathrm{TiB}$ in the lamellar microstructure might exert no influence on the fatigue improvement. In this case, only colony refinement is responsible for fatigue improvement.

\section{Conclusion}

The beneficial effect of adding a minor amount of $\mathrm{B}$ to refine microstructures of a Ti-6Al-4V alloy was confirmed in the as-cast condition and a full lamellar microstructure. For example, the prior $\beta$ grain size of the 0.1 mass $\%$ B-modified alloy with a full lamellar microstructure went from around 1000 to $80 \mu \mathrm{m}$; accordingly, the colony size within the grains was reduced. Contrary to this, the same equiaxed microstructures with $\alpha$ grain sizes of about $8 \mu \mathrm{m}$ were obtained for both B-free and B-modified alloys when they were hotdeformed and annealed in the $(\alpha+\beta)$ two phase region. The room temperature high cycle fatigue (HCF) strength of Bmodified alloys increased compared to the B-free alloy for both microstructures. For example, the HCF strength at $10^{7}$ cycles for the alloy with an equiaxed microstructure increased to $750 \mathrm{MPa}$ by the addition of 0.1 mass $\% \mathrm{~B}$, from $650 \mathrm{MPa}$ for B-free alloy. Fatigue cracks were found to originate neither from the $\mathrm{TiB} /$ matrix interface nor from the TiB itself but rather from shear fractures across microstructural units such as colonies or spherical $\alpha$ phases. The reduced colony size and the retarding effect of $\mathrm{TiB}$ against the movement of the fatigue initiation area were thought to be responsible for the improved $\mathrm{HCF}$ properties of Ti-6Al-4V with lamellar and equiaxed microstructures, respectively. 


\section{REFERENCES}

1) S. Tamirisakandala, R. B. Bhat, J. S. Tiley and D. B. Miracle: Scr. Mater. 53 (2005) 1421-1426.

2) B. Cherukuri, R. Srinivasan, S. Tamirisakandala and D. B. Miracle: Scr. Mater. 60 (2009) 496-499.

3) S. Tamirisakandala, R. B. Bhat, J. S. Tiley and D. B. Miracle: J. Mater. Eng. Perform. 14 (2005) 741-746.

4) R. Srinivasan, D. Miracle and S. Tamirisakandala: Mater. Sci. Eng. A 487 (2008) 541-551.

5) R. Srinivasan, M. D. Bennett, S. Tamirisakandala, D. B. Miracle, K.-O. Yu and F. S. Sun: J. Mater. Eng. Perform. 18 (2009) 390-398.

6) I. Sen, K. Gopinath, R. Jatta and U. Ramamurty: Acta Metall. 58 (2010) 6799-6809.

7) S. Roy, A. Sarkar and S. Suwas: Mater. Sci. Eng. A 528 (2010) 449
458.

8) S. Roy, S. Suwas, S. Tamirisakandala, D. B. Miracle and R. Srinivasan: Acta Metall. 59 (2011) 5494-5510.

9) M. Hagiwara, A. Araoka and S. Emura: Metall. Mater. Trans. A 35 (2004) 2161-2170.

10) M. Hagiwara, Y. Kaieda, Y. Kawabe and S. Miura: ISIJ Int. 31 (1991) 922-930.

11) D. Eylon and J. A. Hall: Metall. Trans. A 8A (1977) 981-990.

12) A. E. Palty, H. Margolin and J. P. Nielsen: Trans. ASM 46 (1954) 312328.

13) S. J. Kim, M. Hagiwara, Y. Kawabe and S. S. Kim: Mater. Sci. Eng. A 334 (2002) 73-78.

14) H. Yokoyama, O. Umezawa, K. Nagai, T. Suzuki and K. Kobuko: Metall. Mater. Trans. A 31 (2000) 2793-2805.

15) O. Umezawa and K. Nagai: ISIJ Int. 37 (1997) 1170-1179. 